\title{
Rendimento do coentro (Coriandrum sativum $L$ ) adubado com esterco bovino em diferentes doses e tempos de incorporação no solo
}

\author{
LINHARES, P.C.F"*; PEREIRA, M.F.S.'; MOREIRA, J.C.'; PAIVA, A.C.C. .; ASSIS, J.P.'; SOUSA, R.P. ${ }^{1}$ \\ 'Universidade Federal Rural do Semi-Árido, Departamento de Fitotecnia, Campus Mossoró, Av. Francisco \\ Mota, Caixa Postal 137, 59625-900, Mossoró, RN, Brasil, '2Cooperativa de Assessoria e Serviços Múltiplos \\ ao Desenvolvimento Rural. Rua Machado de Assis 125, CEP 59610-030, Mossoró, RN, Brasil. *Autor para \\ correspondência; E- mail: paulojitirana@yahoo.com.br.
}

\begin{abstract}
RESUMO: O uso de esterco bovino é de suma importância para os agricultores familiares que produzem coentro na região de Mossoró-RN, pois esse insumo é amplamente disponível e utilizado pelos agricultores. Objetivando-se avaliar o Rendimento do coentro fertilizado com esterco bovino em diferentes doses e tempos de incorporação ao solo foi conduzido um experimento no período de setembro a novembro de 2011, na Fazenda Experimental Rafael Fernandes, da Universidade Federal Rural do Semi-Árido - UFERSA, Brasil. Os tratamentos consistiram da combinação de quatro doses de esterco bovino incorporadas ao solo: 15,0; 30,0; 45,0 e 60,0 tha-1 em base seca, com quatro tempos de incorporação: 28; 49; 64 e 80 dias antes da semeadura do coentro - DAS, mais um tratamento controle (ausência de adubação). $O$ delineamento experimental utilizado foi em blocos completos casualizados com os tratamentos arranjados em esquema fatorial $4 \times 4+1 \mathrm{com} 3$ repetições. A cultivar de coentro utilizado foi a Verdão e as variáveis determinadas foram altura e número de hastes por planta e rendimento de coentro. O coentro respondeu à aplicação de esterco bovino, produzindo rendimentos máximos de 6453 e $6349 \mathrm{~kg} \mathrm{ha}^{-1}$ de massa verde, com a dose de $60 \mathrm{t} \mathrm{ha}^{-1} \mathrm{e}$ aos quarenta e seis dias de incorporação antes da semeadura, respectivamente.
\end{abstract}

Palavras-chave: planta condimentar, hortaliça, adubação orgânica.

\begin{abstract}
Yield of the coriander [Coriandrum sativum (L.)] fertilized with manure at different doses and incorporation times in the soil. The use of manure is very important to family farmers who produce coriander in the region of Mossoró-RN, because this input is widely available and used by farmers. Aiming to evaluate the yield of the coriander fertilized with manure at different doses and incorporation times in the soil, a trial was conducted from September to November 2011, at the Experimental Farm Rafael Fernandes in the Universidade Federal Rural do Semi-Árido (UFERSA), Mossoró-RN, Brazil. The treatments consisted on the combination of four levels of manure incorporated into the soil: 15.0; 30.0; 45.0 and $60.0 \mathrm{tha}^{-1}$ at dry basis, with four incorporation times: $28 ; 49 ; 64$ and 80 days before the coriander's sowing - DAS, plus a control treatment (without fertilization). The experimental design was a randomized complete block with treatments arranged in a $4 \times 4+1$, with three replications. The coriander planted was the "Verdão" and the specific variables were height and number of stalks per plant and yield of the coriander. The coriander responded to the application of the manure, producing maximum yields of 6453 and $6349 \mathrm{~kg} \mathrm{ha}^{-1}$ of fresh mass, with the dose of $60 \mathrm{t} \mathrm{ha}^{-1}$ and at forty-six days of incorporation before the sowing, respectively.
\end{abstract}

Keywords: condiment plant, greenery, organic fertilization.

\section{INTRODUÇÃO}

A agricultura orgânica é um sistema de produção que pressupõe conservar os recursos naturais e melhorar a qualidade dos produtos, buscando a produção econômica de alimentos sem resíduos tóxicos. Nesse sistema de produção, os adubos minerais são substituídos pelos orgânicos e os agrotóxicos pelos defensivos naturais (Santos \& Santos, 2007). O cultivo orgânico de olerícolas tem 
crescido nos últimos anos, devido principalmente aos efeitos benéficos do material orgânico sobre as características físicas e químicas do solo, e também pelo alto custo dos adubos minerais. Esta fertilização não só incrementa a produtividade, mas também proporciona a obtenção de plantas com características qualitativas distintivas daquelas cultivadas exclusivamente com fertilizantes minerais (Peixoto Filho, 2006). Entre as fontes orgânicas de maior uso destacam-se, os estercos, que na região de Mossoró-RN, o de origem bovina é um dos mais utilizado pelos produtores de coentro, dado ao aspecto cultural da região em criação de bovino para a produção de leite e carne.

Segundo Nascimento \& Pereira, (2003), o coentro (Coriander sativum L.) é uma olerícola de grande valor e importância comercial. No Brasil, tem sido cultivado por pequenos e médios produtores, tanto para a produção de massa verde, comercializada em feiras livres e supermercados, como também para a produção de frutos, utilizado nas indústrias alimentícias e cosméticas (Oliveira et al., 2005). Na região de Mossoró-RN, essa olerícola é explorada exclusivamente para a produção de folhas verdes. Várias localidades em torno desse município, a produção se dá de forma orgânica, utilizando mão de obra familiar e comercializando a produção nas feiras orgânicas e supermercados. Nessas áreas de produção, o esterco bovino é o resíduo orgânico mais utilizado, principalmente por agricultores com baixo nível tecnológico.

O manejo eficiente de estercos para a adubação de cultivos agrícolas requer o conhecimento da dinâmica de mineralização de nutrientes, buscando otimizar a sincronização do momento de demanda da cultura em relação a disponibilidade no solo de nutrientes evitando a imobilização ou a rápida mineralização de nutrientes durante os períodos de alta ou de baixa demanda, respectivamente (Figueiredo et al., 2012).

Essa tem sido uma das preocupações dos produtores de coentro local no que tange a dose e o tempo entre a incorporação e plantio, tendo em vista que pela falta de informações, o produtor só passa ter um rendimento satisfatório a partir do segundo cultivo, já que, por ser uma cultura de ciclo curto (30 dias na região de Mossoró) a aplicação do esterco por ocasião do cultivo possivelmente não atende a necessidade da cultura. A incubação do esterco irá proporcionar condições satisfatória no que tange a disponibilidade de nutrientes no momento de maior exigência da cultura.

Diante da necessidade de se esclarecer a dose e a época da aplicação de esterco bovino adequadas na produção orgânica, objetivaramse avaliar o rendimento do coentro adubado com esterco bovino em diferentes doses e tempos de incorporação do esterco bovino antes da semeadura.

\section{MATERIAL E MÉTODOS}

O experimento foi conduzido na Fazenda Experimental Rafael Fernandes, localizada no distrito de Alagoinha, zona rural de Mossoró-RN, no período de setembro a novembro de 2011, em solo classificado como Latossolo Vermelho Amarelo Argissólico franco arenoso (EMBRAPA, 2006). O distrito de Alagoinha está situado nas seguintes coordenadas: latitude 5.03'37's e longitude de 37'23'50"W Gr, com altitude de aproximada de $72 \mathrm{~m}$, distando $20 \mathrm{~km}$ da cidade de Mossoró-RN. Segundo Thornthwaite, o clima local é DdAa', ou seja, semi-árido, megatérmico e com pequeno ou nenhum excesso d'água durante o ano, e de acordo com Köppen é BSwh', seco e muito quente, com duas estações climáticas: uma seca, que geralmente compreende o período de junho a janeiro e uma chuvosa, entre os meses de fevereiro e maio (Carmo filho et al., 1991).

Antes da instalação do experimento foram retiradas amostras de solo na camada de $0-20 \mathrm{~cm}$, as quais foram secas ao ar e peneirada em malha de $2 \mathrm{~mm}$, em seguida foram analisadas no Laboratório de Química e Fertilidade de Solos da UFERSA, cujos resultados foram os seguintes: $\mathrm{pH}$ (água 1:2,5) = 6,45; cátions trocáveis $\mathrm{Ca}=1,84 \mathrm{cmol}_{\mathrm{c}} \mathrm{dm}^{-3} ; \mathrm{Mg}=$ $0,37 \mathrm{cmol}_{\mathrm{c}} \mathrm{dm}^{-3} ; \mathrm{K}=0,14 \mathrm{cmol}_{\mathrm{c}} \mathrm{dm}^{-3} ; \mathrm{Na}=0,12 \mathrm{cmol}_{\mathrm{c}}$ $\mathrm{dm}^{-3} ; \mathrm{P}$ (Mehlich) $=3,40 \mathrm{mg} \mathrm{dm}^{-3} \mathrm{e}$ M.O. $=5,5 \mathrm{~g} \mathrm{~kg}^{-1}$.

Os tratamentos consistiram da combinação de quatro doses de esterco bovino incorporadas ao

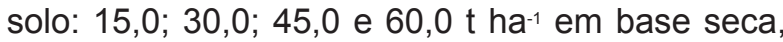
com quatro tempos de incorporação: 28; 49; 64 e 80 dias antes da semeadura do coentro - DAS, mais um tratamento controle (ausência de adubação). O delineamento experimental utilizado foi em blocos completos casualizados com os tratamentos arranjados em esquema fatorial $4 \times 4+1 \mathrm{com} 3$ repetições.

Cada parcela constou de seis fileiras de plantas espaçadas de $0,2 \mathrm{~m} \times 0,05 \mathrm{~m}$ com quarenta e oito plantas por fileiras, sendo as fileiras laterais consideradas bordaduras. A área total das parcelas foi de $1,44 \mathrm{~m}^{2}$ e a área útil de $0,80 \mathrm{~m}^{2}$, contendo 192 plantas, com duas plantas por cova. O preparo do solo consistiu da limpeza manual com enxada, retirada do material para fora da área experimental seguida de uma gradagem e levantamento dos canteiros, realizado manualmente utilizando enxada.

O esterco bovino utilizado apresentavase estabilizado e foi proveniente da criação de novilhas do setor de bovinocultura da UFERSA, criadas no sistema intensivo, alimentadas com concentrado à base de milho, soja e farelo de trigo e tendo como volumoso, o capim canarana 
(Echinocloa polystochya). Por ocasião da instalação do experimento foram retiradas cinco amostras do montante de esterco utilizado, que foram analisadas no laboratório de fertilidade do solo e nutrição de plantas do Departamento de Ciências Ambientais e Tecnológicas da UFERSA, tendo como resultados médios os seguintes valores: $\mathrm{pH}$ (água 1:2,5) =8,06; e os teores totais de $19,7 \mathrm{~g} \mathrm{~kg}^{-1}$ de N; $0,767 \mathrm{~g} \mathrm{~kg}^{-1}$ de $\mathrm{P} ; 6,827 \mathrm{~g} \mathrm{~kg}^{-1}$ de $\mathrm{K}^{+} ; 2,449 \mathrm{~g} \mathrm{~kg}^{-1}$ de Na+; 0,197

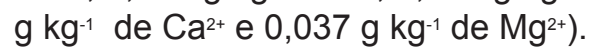

Durante os tempos de incorporação, fizeram-se irrigações com a finalidade de manter a umidade do solo entre $70 \%$ da capacidade de campo, sendo essa, uma condição ideal para o processo de mineralização (Meurer et al., 2007).

A variedade de coentro utilizada foi a "Super verdão", utilizada na região durante o período chuvoso, cultivada em semeadura direta, colocandose seis sementes por cova.

Dez dias após a emergência (DAE), foi realizado o desbaste das parcelas, deixando-se duas plantas por cova, perfazendo uma população de $2,0 * 10^{6}$ plantas ha-1. Durante a condução do experimento foram efetuadas regas diárias, para manutenção da umidade adequada no solo, e capinas manuais, para o controle da competição entre as plantas.

Aos trinta e cinco dias após a semeadura (DAS) realizou-se a colheita do experimento. Foram realizadas avaliações das variáveis: altura de planta (cm planta-1), número de hastes por planta (média por planta) e rendimento de massa verde $\left(\mathrm{kg} \mathrm{ha}^{-1}\right)$. A altura de planta foi mensurada em amostra de vinte plantas da base até o ápice, utilizando uma régua milimetrada. O número de hastes foi determinado em amostra de vinte plantas e expresso pela média. $\mathrm{O}$ rendimento de coentro foi determinado em $70 \%$ de área total, já que os espaços entre os canteiros não são cultivados, expressando-se a massa por $\mathrm{m}^{2} \mathrm{de}$ canteiro em área de um ha. A massa foi determinada com precisão para 1,0 g após o corte acima do colo da planta.

Realizou-se análise univariada da variância em cada variável do coentro, através do aplicativo software ESTAT (Kronka \& Banzato, 1995). O procedimento de ajustamento de curva de resposta foi realizado através do software Table Curve (Jandel Scientific, 1991). As funções respostas foram avaliadas com base nos seguintes critérios: lógica biológica, significância do quadrado médio do resíduo da regressão ( $Q M R r)$, alto valor do coeficiente de determinação $\left(R^{2}\right)$ e, significância dos parâmetros da regressão, utilizando-se o teste t ao nível de $5 \%$ de probabilidade.

\section{RESULTADO E DISCUSSÃO}

Não houve interação entre as doses de esterco bovino e os tempos de incorporação para altura de planta, número de hastes e rendimento. Assim, as doses de esterco bovino tiveram comportamento semelhante dentro de cada tempo de incorporação (Tabela 1).

Uma curva ascendente da altura de planta foi ajustada em função das doses de esterco bovino adicionadas ao solo (Figura 1a). A altura máxima foi $18,1 \mathrm{~cm}$ obtida com a dose de $60,0 \mathrm{t}$ ha-1 ${ }^{-1}$ correspondendo a um acréscimo médio de $5,1 \mathrm{~cm}$ em relação à menor dose $(15,0 \mathrm{t}$ ha-1). Comportamento diferente foi observado para os tempos de incorporação (Figura 1b), pois nesse caso a altura de plantas variou em função do tempo seguindo a função inversa de segundo grau. $O$ ponto de máximo foi estimado aos quarenta e sete dias, chegando a $15,6 \mathrm{~cm}$ planta-1 $^{-1}$ que correspondeu ao acréscimo de $1,8 \mathrm{~cm}$ planta $^{-1}$, em relação ao tempo de oitenta dias de incorporação. Esses resultados são superiores ao encontrado por Linhares, (2009) estudando o uso de adubo verde com espécies espontâneas da caatinga no rendimento do coentro

TABELA 1. Valores de $\mathrm{F}$ para altura de plantas (AT), número de hastes por planta (NH), rendimento de massa verde de coentro (RC) fertilizado com doses de esterco bovino em quatro tempos de incorporação. MossoróRN, UFERSA, 2011.

\begin{tabular}{|c|c|c|c|c|}
\hline Causas de Variação & $\mathrm{GL}$ & AT $(\mathrm{cm})$ & $\mathrm{NH}$ & $\mathrm{RC}$ \\
\hline Doses de esterco bovino $(A)$ & 3 & $11,14^{\prime \prime}$ & $25,39^{\prime \prime}$ & $37,55^{\star}$ \\
\hline Tempos de incorporação (B) & 3 & $36,08^{* *}$ & 24,57 & $19,58^{*}$ \\
\hline$A \times B$ & 9 & 1,26 ns & $1,24^{\text {ns }}$ & $2,07 \mathrm{~ns}$ \\
\hline Testemunha $\times$ Fatorial & 1 & 22,15 & 30,12 & 40,85 \\
\hline Tratamentos & 17 & $10,31^{* *}$ & $1,64^{n . s}$ & 14,96 \\
\hline Blocos & 2 & 6,05 & $4,84^{\circ}$ & 6,22 \\
\hline Resíduo & 30 & --- & $\begin{array}{ll}----- \\
\end{array}$ & $\begin{array}{ll}----- \\
\end{array}$ \\
\hline CV (\%) & --- & 8,03 & 8,47 & 12,58 \\
\hline Média Geral & --- & 13,90 & 7,37 & 5432 \\
\hline
\end{tabular}

${ }^{* *}=\mathrm{P}<0,01 ;{ }^{*}=\mathrm{P}<0,05 ;$ ns $=\mathrm{P}>0,05$

Rev. Bras. PI. Med., Campinas, v.17, n.3, p.462-467, 2015. 
e observou valor médio de $14,8 \mathrm{~cm}$ planta-1. Essa diferença se deve provavelmente à quantidade de esterco bovino utilizado no atual trabalho ter sido amplamente maior, o que contribuiu para uma altura de planta expressiva, semelhante à encontrada nas hortas de agricultores familiares da região que também aplicam doses altas de esterco bovino.

O número de hastes apresentou acréscimo médio de uma haste planta-1, na maior $\left(60,0 \mathrm{t} \mathrm{ha}^{-1}\right)$ em relação à menor dose de esterco bovino $(15,0$ t ha-1) incorporado ao solo, com valor médio de 6,3 hastes planta-1 (Figura 2a). Em relação aos tempos de incorporação, o de 44 dias foi o que promoveu a maior média, com valor de 6,6 hastes planta-1 (Figura 2b). Esses valores foram superiores ao encontrado por Jales et al. (2006) estudando o desenvolvimento do coentro cultivado com húmus de minhoca que obtiveram 5,10 hastes por plantas. A menor quantidade de adubo orgânico aplicado naquele estudo que foi $20 \mathrm{t} \mathrm{ha}^{-1}$ de húmus de minhoca possivelmente foi o que contribuiu para um número de hastes inferior na referida pesquisa.

O rendimento aumentou em função da dose de esterco bovino ao solo, chegando a $6453 \mathrm{~kg} \mathrm{ha}^{-1}$ na dose de $60 \mathrm{t} \mathrm{ha}^{-1}$ de esterco bovino (Figura 3a). Já em relação ao tempo de incorporação, o ponto de máximo rendimento foi estimado em quarenta e seis dias antecedentes à semeadura que possibilitou rendimento de $6349 \mathrm{~kg} \mathrm{ha}^{-1}$ (Figura 3b). Assim, a maior disponibilidade de nutrientes provavelmente fornecidos pelo esterco bovino ocorreu após 46 dias de incorporação antes da semeadura. Esse período proporcionou um rendimento expressivo dado possivelmente à sincronia entre o momento de maior exigência nutricional da cultura em relação à mineralização do material orgânico e consequentemente a disponibilidade de nutrientes ao solo.

Linhares et al. (2012) avaliando quantidades

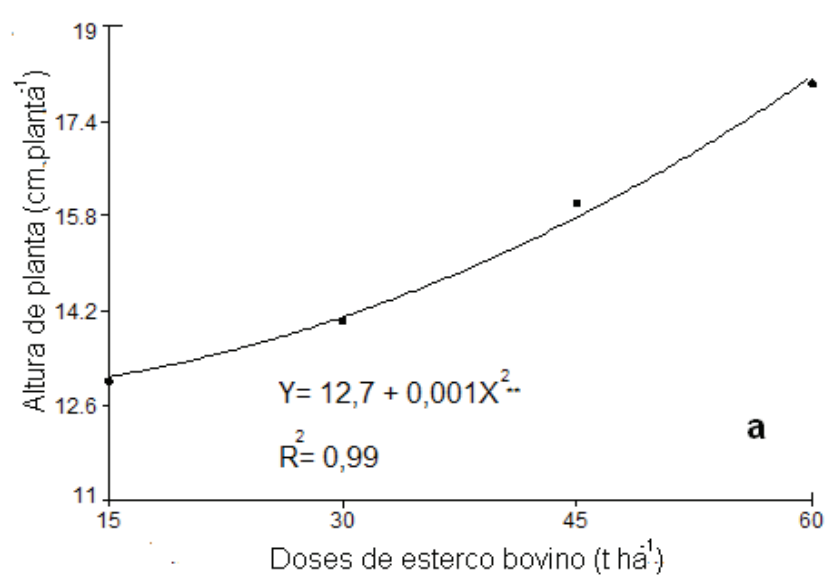

e tempos de decomposição da jitirana no desempenho agronômico do coentro, encontraram produtividade de 7064 e $6176 \mathrm{~kg} \mathrm{ha}^{-1}$ com a dose $15,6 \mathrm{t} \mathrm{ha}^{-1}$ e no tempo de incorporação de 30 dias antes a semeadura, respectivamente, sendo superiores aos observados no atual estudo. Essa superioridade provavelmente se deve à concentração de nutrientes na jitirana ser superior à do esterco bovino, com teor de nitrogênio, fósforo e potássio da ordem de 25,6 $\mathrm{g} \mathrm{kg}^{-1} ; 11,0 \mathrm{~g} \mathrm{~kg}^{-1}$ e $10,0 \mathrm{~g} \mathrm{~kg}^{-1}$, respectivamente. Além disso, por ser um material bastante lábil e com relação $\mathrm{C} / \mathrm{N}$ de $18 / 1$, contribuiu provavelmente para que o processo de mineralização ocorresse em tempo hábil, atendendo as exigências nutricionais do coentro.

O rendimento na ausência de adubação (988 $\mathrm{kg} \mathrm{ha}^{-1}$ ) representou apenas $15 \%$ do máximo obtido nesse estudo (Tabela 2). Isso indica que a produtividade alta, que chegou a $6453 \mathrm{~kg} \mathrm{ha}^{-1}$ obtida nessa pesquisa se deve provavelmente ao fornecimento de nutrientes pelas maiores doses de esterco bovino, já que, o solo empregado no experimento apresentava anteriormente baixos teores de matéria orgânica no solo $(5,5$ $\left.\mathrm{g} \mathrm{kg}^{-1}\right)$ e fósforo disponível $\left(3,4 \mathrm{mg} \mathrm{dm}^{-3}\right)$, o que provavelmente não atendeu as necessidades da cultura no tratamento controle. Segundo Oliveira et al. (2004) a dose ótima de fósforo para o coentro é de $110 \mathrm{~kg} \mathrm{ha}^{-1}$, em Latossolo Vermelho-Amarelo o que maximiza a produção. O esterco bovino é um dos resíduos orgânicos com maior potencial de uso como fertilizante, principalmente por pequenos agricultores (Alves et al., 2005).

Assim, pode-se concluir que o rendimento do coentro variou com a dose e com a época de aplicação de esterco bovino, produzindo valores máximos de 6453 e $6349 \mathrm{~kg} \mathrm{ha}^{-1}$ de massa verde com a dose de 60 tha-1 $^{-1}$ e aos quarenta e seis dias de incorporação antes da semeadura, respectivamente.

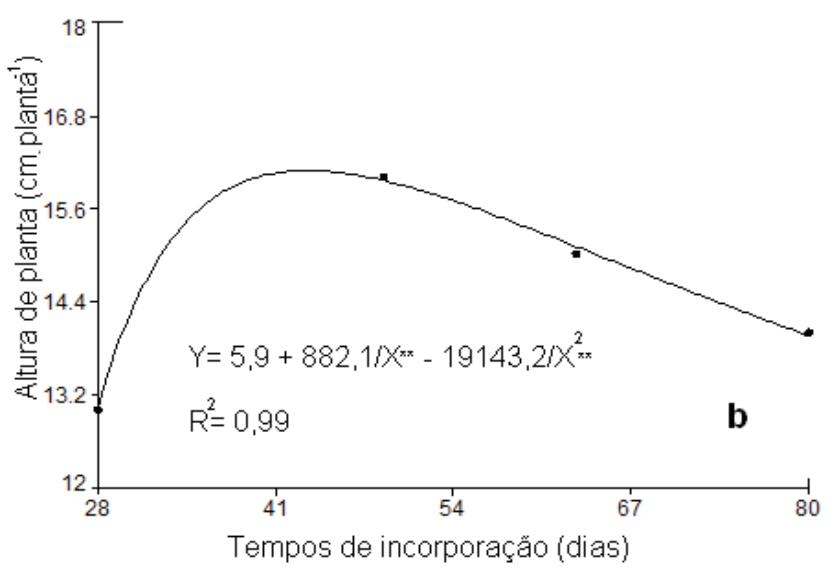

FIGURA 1. Altura de planta de coentro em função da dose (a) e do tempo (b) de incorporação de esterco bovino em Latossolo Vermelho Amarelo. Mossoró RN, UFERSA, 2011. 

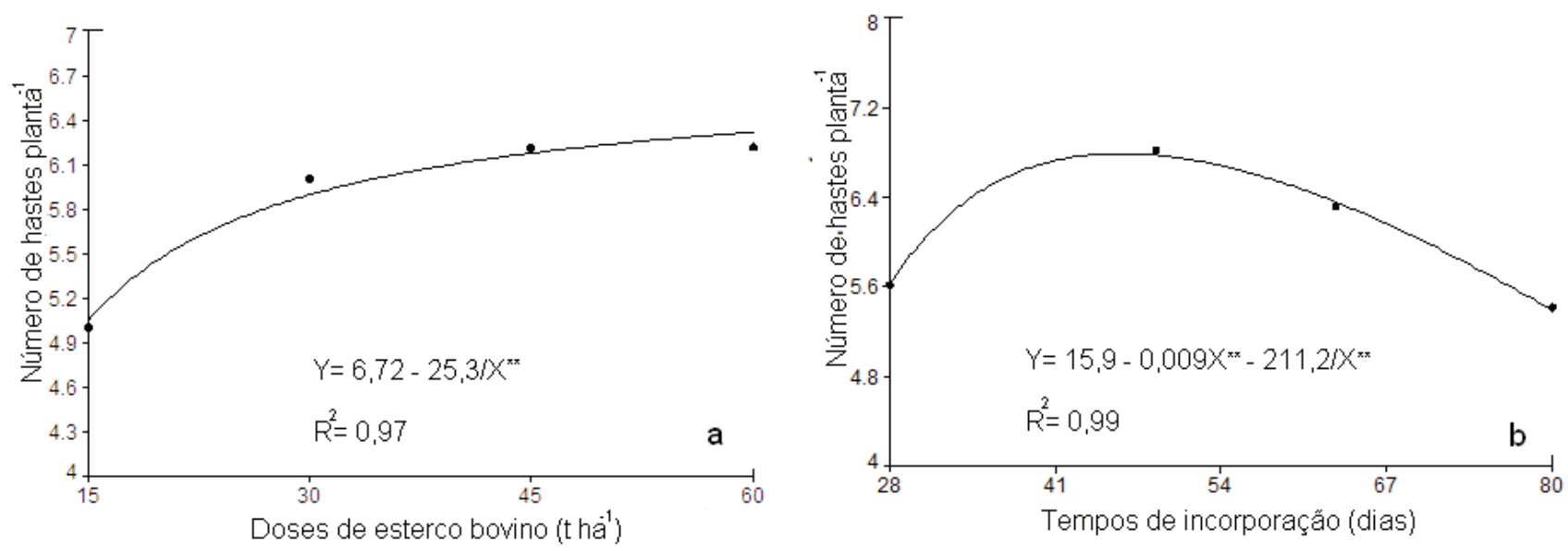

FIGURA 2. Número de hastes de plantas de coentro em função da dose (a) e do tempo (b) de incorporação de esterco bovino em Latossolo Vermelho Amarelo. Mossoró RN, UFERSA, 2011.
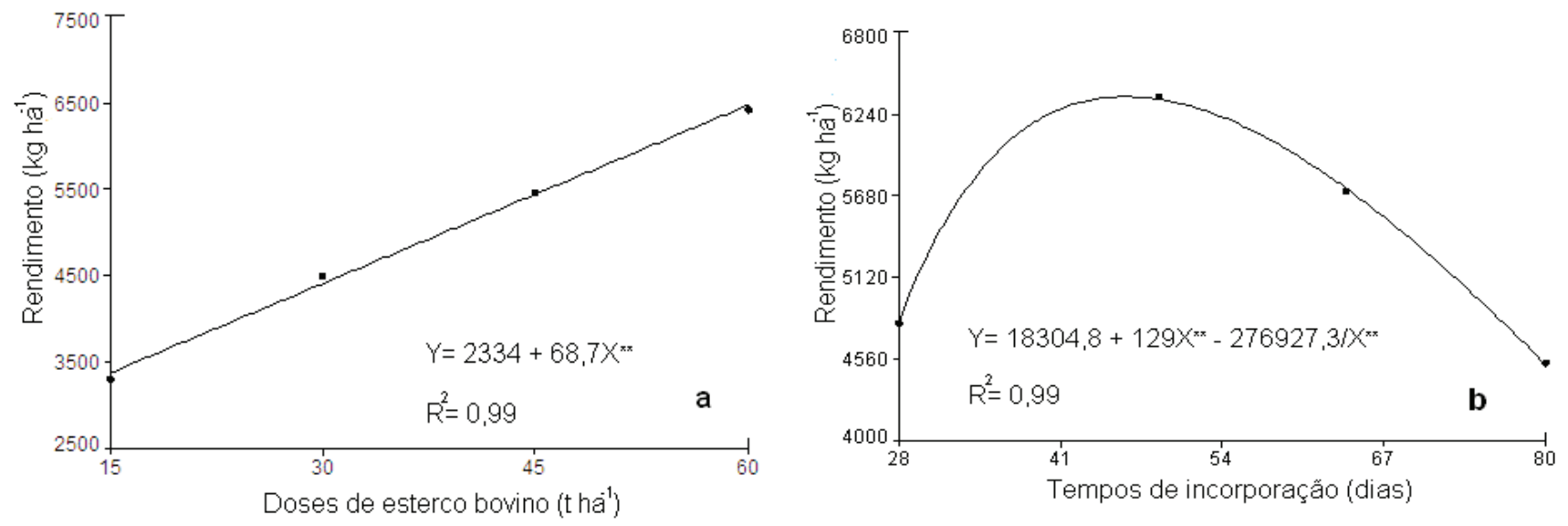

FIGURA 3. Rendimento de coentro em função da dose (a) e do tempo (b) de incorporação de esterco bovino em Latossolo Vermelho Amarelo. Mossoró RN, UFERSA, 2011.

TABELA 2. Valores médios de altura de plantas (AT), número de hastes por planta $(\mathrm{NH})$, rendimento de coentro (RC) e massa seca (MS) de coentro na ausência de adubação com esterco bovino. Mossoró-RN, UFERSA, 2011.

\begin{tabular}{llllc}
\hline Tratamento adicional & AT (cm planta) & $\mathrm{NH}$ & $\mathrm{RR}\left(\mathrm{kg} \mathrm{ha}{ }^{-1}\right)$ & $\begin{array}{l}\text { Massa da matéria seca } \\
\left(\mathrm{kg} \mathrm{ha}^{-1}\right)\end{array}$ \\
\hline Ausência de adubação & 8,2 & 4,6 & 980 & 115
\end{tabular}

\section{AGRADECIMENTOS}

Ao Grupo de Pesquisa Jitirana e á UFERSA - Mossoró/RN, por oferecerem aparato físico para o desenvolvimento dos trabalhos.

\section{REFERÊNCIA}

ALVES, E.U. et al. Rendimento e qualidade fisiológica de sementes de coentro cultivado com adubação orgânica e mineral. Revista Brasileira de Sementes, v. 27, n. 1, p.132-137, 2005.

CARMO FILHO, F. do.; ESPÍNOLA SOBRINHO, J.; MAIA NETO, J.M. Dados climatológicos de Mossoró: 1.ed. Mossoró: Coleção mossoroense, 1991. $121 \mathrm{p}$.
EMPRESABRASILEIRADE PESQUISAAGROPECUÁRIA - EMBRAPA. Sistema brasileiro de classificação de solos. 2.ed. Rio de Janeiro: Embrapa, 2006. 306 p.

FIGUEIREDO C.C. et al. Mineralização de esterco de ovinos e sua influência na produção de alface. Horticultura Brasileira, v.30, n.1, p.175-179, 2012.

JALES, F.E.B. et al. Estudo do desenvolvimento do coentro (cv verdão) cultivado com o húmus de minhoca vermelha da Califórnia. Revista Verde de Agroecologia e Desenvolvimento Sustentável, v. 1, n. 2, p. 34-40, 2006.

JANDEL SCIENTIFIC. Table curve: curve fitting software. Corte Madera, CA: Jandel Scientific, 1991. 280 p.

KRONKA, S.N.; BANZATO, D.A. ESTAT: sistema para análise estatística versão 2. 3. ed. Jaboticabal: Funep, 1995. $243 p$. 
LINHARES, P.C.F. 2009. Vegetação espontânea como adubo verde no desempenho agroeconômico de hortaliças folhosas. 92p. Tese (Doutorado em Fitotecnia) - Universidade Federal Rural do SemiÁrido. UFERSA. Mossoró. RN.

LINHARES, P.C.F. et al. Quantidades e tempos de decomposição da jitirana no desempenho agronômico do coentro. Revista Ciência Rural, v.42, n.2, p. 243248, 2012.

MEURER, E.J. Fatores que influenciam o crescimento e o desenvolvimento das plantas. In: NOVAIS, R.F.; ALVAREZ, V.V.H.; BARROS, N.F.; FONTES, R.L.F.; CANTARUTI, R. B.; NEVES, J.C.L: Fertilidade do solo. 1.ed. Viçosa: Sociedade Brasileira de Ciência do Solo, 2007, 65-90.

NASCIMENTO W.M; PEREIRA R.S. 2003. Coentro: produção e qualidade de sementes. In: Horticultura Brasileira 21, Suplemento 1. CD-ROM.

OLIVEIRA, A.P. et al. Resposta do coentro à adubação fosfatada em solo com baixo nível de fósforo. Horticultura Brasileira, v. 22, n. 1, p. 87-89, 2004.

OLIVEIRA E.Q. et al. Produção e valor agroeconômico no consórcio entre cultivares de coentro e de alface. Horticultura Brasileira, v. 23, n. 2, p. 285-289, 2005.

PEIXOTO FILHO J.U. Produtividade de alface com o uso de diferentes fontes de matéria orgânica e efeito na fertilidade do solo. 2006. 62f. Dissertação (Mestrado em Ciência do Solo) - Universidade Federal Rural de Pernambuco, 2006.

SANTOS, dos J.G.R.; SANTOS, dos E.C.X.R Agricultura Orgânica: Teoria e Prática. Editora da Universidade Estadual da Paraíba, 2007. 228p. 